\title{
Malignant Small Intestinal Neoplasm
}

National Cancer Institute

\section{Source}

National Cancer Institute. Malignant Small Intestinal Neoplasm. NCI Thesaurus. Code

C7523.

A primary or metastatic malignant neoplasm involving the small intestine. 